\title{
Polymerase Chain Reaction Detection and Phylogenetic Characterization of an Agent Associated with Yellow Vine Disease of Cucurbits
}

\author{
Francisco J. Avila, Benny D. Bruton, Jacqueline Fletcher, J. L. Sherwood, Sam D. Pair, and Ulrich Melcher
}

First author: Department of Plant Pathology, University of Nebraska, Lincoln 68583; second and fifth authors: United States Department of Agriculture, Agricultural Research Service, Lane, OK 74555; third and fourth authors: Department of Plant Pathology; and sixth author: Department of Biochemistry and Molecular Biology, Oklahoma State University, Stillwater 74078. Accepted for publication 23 January 1998.

\begin{abstract}
Avila, F. J., Bruton, B. D., Fletcher, J., Sherwood, J. L., Pair, S. D., and Melcher, U. 1998. Polymerase chain reaction detection and phylogenetic characterization of an agent associated with yellow vine disease of cucurbits. Phytopathology 88:428-436.

Diagnosis of yellow vine disease (YVD) in cucurbits, an important disease in the south-central United States, relies on external symptom appearance, phloem discoloration, and the presence of bacterium-like organisms (BLOs) in phloem. Polymerase chain reaction (PCR) amplification of BLO nucleotide sequences was explored as a means to improve diagnostic techniques. PCR, using a primer pair based on sequences of the citrus-greening BLO, amplified a 0.15-kilobase (kb) fragment from the DNA of symptomatic plants, but not from that of asymptomatic plants. Its nucleotide sequence suggested that the DNA amplified was of prokaryotic origin. A primer pair, designed to amplify nonspecific prokaryotic $16 \mathrm{~S}$ rDNA, amplified a 1.5 -kb DNA fragment in both the symptomatic
\end{abstract}

ABSTRACT

In 1988, a new vine decline of cucurbits was observed in Oklahoma. First observed in squash and pumpkin (Cucurbita pepo L.) (6), the disease was not observed in other cucurbits until 1991, when it destroyed much of the early-planted watermelon (Citrullus lanatus (Thunb.) Matsum. \& Nakai) and cantaloupe (Cucumis melo L.) in central Texas and Oklahoma $(5,7,8)$. Early-planted watermelon and cantaloupe can be severely affected by the disease, whereas crops planted after 15 June may have little or no incidence. This disease has never been observed in cucumber.

Symptoms of this disease, called yellow vine disease (YVD), normally appear 10 to 15 days prior to fruit maturity and are similar in cantaloupe, pumpkin, watermelon, and squash (5-8). Leaves change from green to lime-yellow, and then to bright yellow. Affected plants gradually decline and exhibit a blighted appearance within 7 to 10 days. In some cases, immature plants may not turn yellow, but wilt and collapse in 1 day. Fruit and flowers on affected plants are not distorted, but watermelon fruit lose their chlorophyll very quickly $(5,7,8)$. The distinguishing characteristic of YVD-affected plants is that the phloem, which normally has a clear or translucent appearance, becomes honey-colored, particularly in the crown area (5-8). Although foliar symptoms of YVD

Corresponding author: B. D. Bruton; E-mail address: bbruton-usda@lane-ag.org

Mention of a trademark, proprietary product, or vendor does not constitute a guarantee or warranty of the product by the USDA and does not imply its approval to the exclusion of other products or vendors that may also be suitable.

Publication no. P-1998-0309-02R

This article is in the public domain and not copyrightable. It may be freely reprinted with customary crediting of the source. The American Phytopathological Society, 1998. and asymptomatic plants. The $1.5-\mathrm{kb}$ fragment from the asymptomatic plants corresponded to chloroplast $16 \mathrm{~S}$ rDNA, and the band from the symptomatic plants was composed of $16 \mathrm{~S}$ rDNAs from both chloroplasts and a prokaryote. The nucleotide sequence of the prokaryotic DNA was determined and used to design three primers (YV1, YV2, and YV3). Fragments of 0.64 and $1.43 \mathrm{~kb}$ were amplified with primers YV1-YV2 and primers YV1-YV3, respectively, from symptomatic plants. Neither primer set yielded fragments from asymptomatic plants, unrelated bacteria, or selected soilborne fungal pathogens of cucurbits. Phylogenetic analysis indicated that the prokaryote is a gamma- 3 proteobacterium. The consistent association of the 0.64 - and $1.43-\mathrm{kb}$ fragments with symptomatic plants suggests that the gamma- 3 proteobacterium may be the causal agent of YVD of cantaloupe, squash, and watermelon.

Additional keywords: Citrullus lanatus, Cucumis melo, Cucurbita pepo, vine decline. are similar to vine decline symptoms caused by soilborne pathogens (7), root degeneration occurs only in the later stages of YVD development $(5,6,8)$. Attempts to reproduce the disease with different preparations from infected plants or by grafting have been unsuccessful (5).

Structures similar to the bacterium-like organisms (BLOs) found associated with citrus greening (17), clover club leaf (32), and several other diseases $(11,19,24,25,29)$, have been observed by electron microscopy in the phloem of YVD-affected plants $(5,7,8)$. Symptoms of YVD in cantaloupe, squash, and watermelon are similar to symptoms associated with BLOs in other plant hosts $(14,19$, $25)$. Although several plant diseases have been attributed to BLOs $(14,17,19,21,24-26,28)$, relatively little is known about these organisms, except for the one associated with citrus greening $(17,18$, 20). A difficulty in the characterization of BLOs, particularly those that are phloem-limited, is the inability to culture these organisms $(6,8,14,19,25)$. Media for cultivation of the xylem-limited BLOs that cause dieback of chinaberry (28) and Pierce's disease of grape (12) do not support growth of the phloem-limited BLO that causes citrus greening (16). Although electron microscopy has been used to detect BLOs in infected plants $(5,11,13,17,25,29)$, this is an expensive and tedious diagnostic method. Serology has been used to detect different strains of the citrus-greening BLO (18), but an antiserum that detects a range of BLOs has not been reported. Polymerase chain reaction (PCR) amplification of the $16 \mathrm{~S}$ rDNA of the citrus-greening BLO (20), and of the uncultured bacterium associated with papaya bunchy top (11), have been used to characterize these agents. Specific primers for detection of the citrus-greening BLO in affected plants and in the insect vector were developed using the 16S rDNA sequence from that organism (20).

To facilitate identification of YVD-affected plants, we have performed PCR using primers that amplify the $16 \mathrm{~S}$ rDNA of citrus- 
greening BLO to identify the diseased plants, designed YVD-specific primers based on the $16 \mathrm{~S}$ rDNA of a prokaryote associated consistently with YVD-affected plants, and characterized the YVDassociated prokaryote phylogenetically based on the 16S prokaryotic rDNA sequence amplified. Preliminary results have been presented $(3,4)$.

\section{MATERIALS AND METHODS}

Plant collection. During the fall of 1995 and summer of 1996, 170 watermelon, 80 squash, and 20 cantaloupe plants exhibiting symptoms of YVD, and a similar number of asymptomatic plants from the same fields, were collected in central Texas and Oklahoma. Plants exhibiting foliar symptoms of YVD with phloem discoloration (determined by light microscopy), but lacking other abnormalities such as nematode injury, root rot, or xylem discoloration, were classified as YVD-affected. Plants lacking foliar symptoms and with normal-appearing phloem were considered asymptomatic for YVD (healthy). Phloem discoloration was used as the most important criterion for YVD assessment.

Fungal and bacterial isolates. Bacterial species used as controls in PCR included known strains of Escherichia coli, Brucella abortus, Serratia marcescens, Pantoea ananatis, and Spiroplasma citri, as well as bacteria isolated from cucurbits. Selected soilborne fungi from the collection of B. D. Bruton included Acremonium cucurbitacearum Alfaro-García, W. Gams \& J. GarcíaJimenez; Fusarium solani (Mart.) Sacc.; F. oxysporum Schlechtend f. sp. niveum (E. F. Sm.) W. C. Snyder \& H. N. Hans, races 0 , 1, and 2; F. equiseti (Corda) Sacc.; F. semitectum Berk. \& Ravenel; Monosporascus cannonballus Pollack \& Uecker; Verticillium dahliae Kleb.; Macrophomina phaseolina (Tassi) Goidanich; Didymella bryoniae (Auersw) Rehm; Rhizoctonia solani Kühn; and Plectosporium tabacinum (Van Beyma) M. E. Palm, W. Gams $\&$ H. Nirenberg. For isolation of bacteria from symptomatic and asymptomatic plants, tissue sections $(3 \mathrm{~cm})$ of root, stem, or crown were rinsed with tap water, and then immersed in $0.5 \%$ sodium hypochlorite for $5 \mathrm{~min}$. The tissues were rinsed several times with sterile distilled water and immersed in $0.01 \%$ cycloheximide in water for $1 \mathrm{~h}$. The terminal $2 \mathrm{~mm}$ of the tissues were removed under aseptic conditions and the tissues then centrifuged in dry, 50 -ml tubes for $5 \mathrm{~min}$ at $8,000 \times g$. The ends of the centrifuged tissues were pressed briefly on the surface of the following media: potato dextrose agar (PDA), nutrient agar (NA), and PD2, the medium used for isolation of the bacterium that causes Pierce's disease (12). The plates were incubated at $27^{\circ} \mathrm{C}$ for $24 \mathrm{~h}$. Single bacterial colonies, selected and submitted to R. Stall, University of Florida, Gainesville, were identified using fatty acid methyl ester analysis.

Plant, bacterial, and fungal DNA isolation. The phloem was isolated from 2 to $3 \mathrm{~g}$ of fresh crown or root tissue of symptomatic and asymptomatic cantaloupe, squash, and watermelon plants using an enzymatic digestion (22). Plant DNA was purified from the isolated phloem using phenol-chloroform (2). All bacterial isolates except $S$. citri were grown in $3 \mathrm{ml}$ of Terrific broth (TB) for $24 \mathrm{~h}$ at $27^{\circ} \mathrm{C}$ with continuous shaking $(250 \mathrm{rpm}) . S$. citri was grown in LD8 broth (10). DNA was extracted using the hexadecyl trimethyl ammonium bromide (CTAB) method (4). Fungal DNA was isolated from 7-day-old potato dextrose broth (PDB) cultures using the phenol-chloroform procedure for plant DNA (2). The following DNAs from plants infected with BLOs or related organisms and from the appropriate healthy plants were obtained from colleagues: DNA from citrus infected with the citrus-greening BLO (provided by M. Garnier, INRA, France), DNA from strawberry plants infected with the marginal chlorosis BLO (provided by M. Garnier), DNA from papaya plants infected with bunchy top (provided by M. J. Davis, University of Florida), and DNA from citrus plants infected with Xylella fastidiosa (provided by D. L. Hopkins, University of Florida).
PCR and primers that amplify prokaryotic DNA. Four different PCR protocols were developed. The conditions for each protocol were optimized to differentiate symptomatic from asymptomatic plants. Protocol I included primers complementary to specific sequences of the $16 \mathrm{~S}$ rDNA of Indian citrus-greening BLO, strain Poona (forward primer: 5'GCGCGTATGCAATACGAGCGGCA3', and reverse primer: 5'GCCTCGCGACTTCGCAACCCAT3') (20). The reaction was performed in a $100-\mu \mathrm{ml}$ mixture containing $2 \mu \mathrm{g}$ of template DNA (treated with ribonuclease at 1 unit per $\mu \mathrm{g}$ of DNA for $30 \mathrm{~min}$ at $37^{\circ} \mathrm{C}$, because RNA interfered with DNA amplification in this protocol), 2.5 units of Taq polymerase, 20 $\mathrm{mM}$ Tris- $\mathrm{HCl}$ ( $\mathrm{pH} 8.4$ ), $50 \mathrm{mM} \mathrm{KCl}, 0.1 \%$ Triton-X 100, each of the four dNTPs at $200 \mu \mathrm{M}, 2.5 \mathrm{mM} \mathrm{MgCl}_{2}$, and each of the primers at $1.0 \mu \mathrm{M}$. The DNA was amplified under the following conditions: $20 \mathrm{~min}$ at $92^{\circ} \mathrm{C} ; 40$ cycles of $60 \mathrm{~s}$ at $92^{\circ} \mathrm{C}, 45 \mathrm{~s}$ at $47^{\circ} \mathrm{C}$, and $90 \mathrm{~s}$ at $72^{\circ} \mathrm{C}$; and final elongation at $72^{\circ} \mathrm{C}$ for $15 \mathrm{~min}$. Taq polymerase was added after the first denaturation. PCR products were analyzed by gel electrophoresis in $2 \%$ agarose. For sequencing, the amplified DNA was separated by electrophoresis in $2 \%$ Metaphor agarose. The bands were isolated from the gel, purified using Qiagen columns (Chatsworth, CA) and submitted to thermal cycle sequencing using a model 373 DNA sequencer (Perkin-Elmer Cetus, Applied Biosystems Division, Foster City, CA). Similar nucleotide sequences were identified by BLAST search (1) of nucleotide sequence databases.

PCR protocol II included primers known to amplify 1.5 kilobase (kb) 16S rDNA from both prokaryotes and chloroplasts (forward primer: 5'AGAGTTTGATCATGGCTCAG3', and reverse primer: 5'AAGGAGGTGATCCAGCCGC3') (20). The PCR reaction mixture differed from that of protocol I by changing the DNA template to $1 \mu \mathrm{g}$, the $\mathrm{MgCl}_{2}$ concentration to $2.0 \mathrm{mM}$, Taq polymerase to 2 units, and each of the four dNTPs to $100 \mu \mathrm{M}$. Bovine serum albumin (BSA) at $200 \mu \mathrm{g} / \mathrm{ml}$ and $\beta$-mercaptoethanol at $10 \mathrm{mM}$ were added to the mixture. The DNA was amplified under the same conditions, except that the initial $92^{\circ} \mathrm{C}$ denaturation was for $10 \mathrm{~min}$.

Digestion of DNA with BclI and EcoRI. The DNA amplified using protocol II was digested with $B c l l$ and EcoRI to determine if the amplified DNA corresponded to the 16S rDNA of prokaryotes or chloroplasts. The chloroplast $16 \mathrm{~S}$ rDNA has one or more restriction sites for $B c l$, while the prokaryotic $16 \mathrm{~S}$ rDNA has none (27). The latter also has a centrally located restriction site for EcoRI (27) absent from chloroplast $16 \mathrm{~S}$ rDNA (pea, EMBL accession no. X55033). PCR products were digested for $12 \mathrm{~h}$ using $10 \mathrm{U}$ of enzyme per $10 \mu \mathrm{l}$ of PCR product, and analyzed in $1 \%$ Metaphor agarose. The $B c l$ I-resistant $1.5-\mathrm{kb}$ bands were isolated from the agarose gel, purified, and sequenced as described previously using the primers of protocol II. Such bands were isolated from PCR products of 10 symptomatic watermelon samples digested with $B c l$ I, 2 asymptomatic watermelon samples digested with EcoRI, and 1 symptomatic watermelon sample subjected to digestion with EcoRI. The sequences were compared by aligning them with one another using AssemblyLIGN software (IBI, Kodak Co., New Haven, CT). Nearly identical sequences were identified as described above.

DNA from 20 symptomatic (15 watermelon and 5 squash) and 10 asymptomatic ( 8 watermelon and 2 squash) plants was digested with $B c l$ I for $2,6,8$, and $12 \mathrm{~h}$ to determine whether coamplification of the chloroplast $16 \mathrm{~S}$ rDNA could be avoided in protocol II. The PCR product from symptomatic plants obtained from the $12 \mathrm{~h}$ digested template was redigested with $B c l$ I and EcoRI to confirm the amplification of prokaryotic DNA. Digested products were analyzed by gel electrophoresis in $1 \%$ agarose.

Cloning the 1.5-kb band of the prokaryotic organism. PCR products were purified using Qiagen columns and ligated with plasmid pCRII (Invitrogen Corp., San Diego, CA) and the products used to transform competent cells of E. coli (XL-1 Blue) using the TA Cloning protocol (Invitrogen Corp.). Plasmids from transformants were purified using alkaline-lysis/polyethylene glycol 
(4). The purified plasmid DNA was analyzed by digestion with EcoRI to identify clones containing an insertion of the $1.5-\mathrm{kb}$ fragment. Clones with inserts were sequenced in both directions as previously described using the primers listed in Table 1. SP6 and T7 primers (Invitrogen Corp.) were used to sequence the ends of the inserts. Partial sequences were assembled using AssemblyLIGN software. The $16 \mathrm{~S}$ rDNA clone sequences were compared with the partial sequences obtained from PCR products to determine their degree of similarity. The alignment was used for phylogenetic analysis and to determine specific sequences from which primers were designed for identification of plants affected by YVD.

Primer design and PCR protocol for detection of plants affected by YVD. Three primers, YV1, YV2, and YV3, were designed for amplification of the sequence represented by the cloned 16S rDNA using two different PCR protocols (III and IV). YV1 is

TABLE 1. Primers designed for sequencing of the $16 \mathrm{~S}$ rDNA of the prokaryote associated with yellow vine disease (YVD) ${ }^{\mathrm{a}}$

\begin{tabular}{lc}
\hline Primer sequence & $\begin{array}{c}\text { Location in the 16S rDNA } \\
\text { of the YVD organism }\end{array}$ \\
\hline 5'TAAAGCGCACGCAGGCG3' $^{\prime}$ Y & 564 to 580 forward \\
5'CGCAAGGTTAAAACTCA3' $^{\prime}$ & 890 to 906 forward \\
5'GGCGTATACAAAGAGAA3' & 1,235 to 1,251 forward \\
5'AGCGATTCCGACTTCAT3' & 1,322 to 1,338 reverse \\
5'TCATCCCCACCTTCCTC3' & 1,170 to 1,185 reverse \\
5'CATCCGAATTAAACCAC3' & 945 to 962 reverse \\
5'GTTGAGCCCGGGGATTT3' & 600 to 616 reverse \\
5'CCCGTAGGAGTCTGGAC3' & 325 to 341 reverse \\
\hline
\end{tabular}

a Insert ends were determined using primers complementary to SP6 and T7 promoters of pCRII as recommended by the manufacturer of the TA Cloning kit (Invitrogen Corp., San Diego, CA). Coordinates refer to GenBank accession no. U82807.

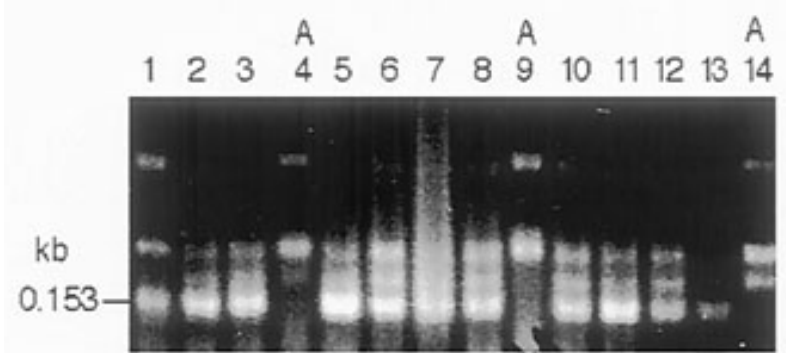

Fig. 1. Agarose gel electrophoresis of polymerase chain reaction products from watermelon plants using primers that amplify $16 \mathrm{~S}$ rDNA of citrus-greening bacterium-like organism (protocol I). Lanes 1, 2, 3, 5, 6, 7, 8, 10, 11, 12, and 13 are products from symptomatic plants and lanes 4,9 , and 14 are products from asymptomatic plants.

TABLE 2. Comparison of yellow vine disease (YVD) symptomatic and asymptomatic watermelon and squash plants by microscopic evaluation and polymerase chain reaction $(\mathrm{PCR})^{\mathrm{a}}$

\begin{tabular}{|c|c|c|c|}
\hline & Total no. & Symptomatic $^{\mathrm{b}}$ & Asymptomatic $^{\mathrm{c}}$ \\
\hline Location, crop, and cultivar & of plants & PCR +d/total & PCR +d/total \\
\hline Tex & 40 & $35 / 35$ & $0 / 5$ \\
\hline Texas & 16 & $10 / 10$ & $0 / 6$ \\
\hline Oklahoma, watermelon, multiple cvs. & 14 & $7 / 7$ & $0 / 7$ \\
\hline Oklahoma, squash, Peto-PC391 & 30 & $20 / 20$ & $1 / 10$ \\
\hline
\end{tabular}

a Plants were collected from fields in Texas and Oklahoma and PCR was performed using primers known to amplify the $16 \mathrm{~S}$ rDNA of the citrus-greening bacterium-like organism (protocol I).

b Samples were considered YVD-symptomatic if the phloem was honey-brown in color when examined by light microscopy.

${ }^{c}$ Samples were considered YVD-asymptomatic if the phloem was normal with translucent appearance when examined by light microscopy.

${ }^{\mathrm{d}}$ Samples were considered positive (+) by PCR if the $0.153-\mathrm{kb}$ band was visible in the gel as shown in Figure 1, and negative if the band was absent. a forward primer of 17 residues, corresponding to the sequence between positions 71 to $87,5^{\prime}$ GGGAGCTTGCTCCCCGG3'. YV2 is a reverse primer of 20 residues, corresponding to the sequence

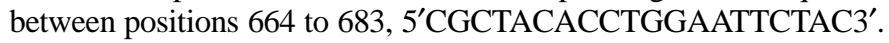
YV3 is a reverse primer of 21 residues, corresponding to the sequence between positions 1,485 to $1,505,5^{\prime}$ GGTTACCTTGTTACGACTTCA3'. PCR protocol III included YV1 as the forward primer and YV2 as the reverse primer. The PCR parameters differed from protocol II in the amount of DNA template at $0.25 \mu \mathrm{g}$, Taq polymerase at 1 unit, $\mathrm{MgCl}_{2}$ at $1.5 \mathrm{mM}$, and in the amplification program of $5 \mathrm{~min}$ at $92^{\circ} \mathrm{C} ; 25$ cycles of $92^{\circ} \mathrm{C}$ for $60 \mathrm{~s}$, $60^{\circ} \mathrm{C}$ for $45 \mathrm{~s}$, and $72^{\circ} \mathrm{C}$ for $90 \mathrm{~s}$; and a final elongation of $15 \mathrm{~min}$ at $72^{\circ} \mathrm{C}$. $\mathrm{Taq}$ polymerase was added at the beginning of the reaction. PCR protocol IV included YV1 as the forward primer and YV3 as the reverse primer. The PCR parameters differed from protocol II in the amount of DNA template at $2 \mu \mathrm{g}$, each of the dNTPs at $200 \mu \mathrm{M}$, and in the amplification program of $10 \mathrm{~min}$ at $92^{\circ} \mathrm{C} ; 30$ cycles of $92^{\circ} \mathrm{C}$ for $60 \mathrm{~s}, 60^{\circ} \mathrm{C}$ for $45 \mathrm{~s}$, and $72^{\circ} \mathrm{C}$ for $90 \mathrm{~s}$.

Phylogenetic characterization of the YVD BLO. RNA secondary structures were predicted using the FOLD application (Genetics Computer Group, Madison, WI). The sequence of the $1.5-\mathrm{kb}$ band was used as a query in BLAST searches to identify closely related sequences, which were aligned using PILEUP software (Genetics Computer Group). The alignments from PILEUP were truncated to the length of the shortest sequence so that the final length of the sequences used for the analysis was $1.4 \mathrm{~kb}$. Phylogenetic analysis by parsimony of 100 bootstrapped replicates utilized applications of the PHYLIP version 3.5 package (16). MEGA (version 1.01; University of Pennsylvania, University Park, PA) was used to analyze the truncated sequences by neighbor joining using Jukes-Cantor distances.

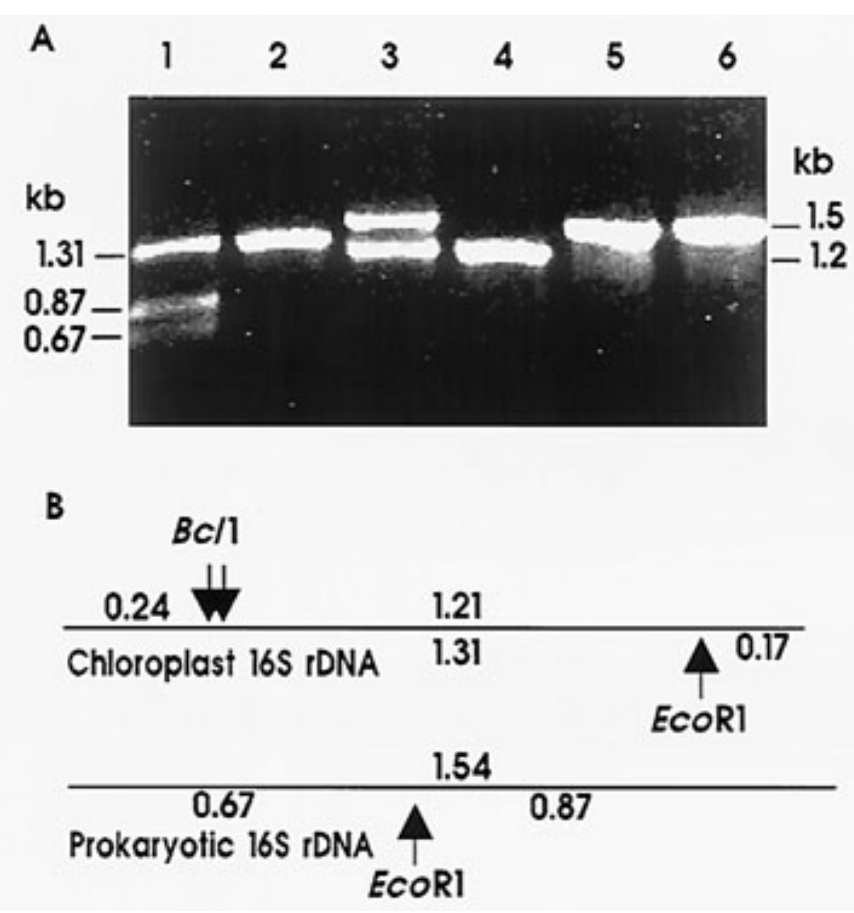

Fig. 2. Restriction analysis of polymerase chain reaction (PCR) products from watermelon plants using primers that amplify 16S rDNA from both chloroplasts and prokaryotes (protocol II). A, Agarose gel electrophoresis of products that were not digested (lanes 5 and 6) or digested with $B c l$ I (lanes 3 and 4) or EcoRI (lanes 1 and 2). PCR templates were from symptomatic plants (lanes 1, 3, and 6) or from asymptomatic plants (lanes 2, 4, and 6). B, Restriction digest cartoon of the $16 \mathrm{~S}$ rDNA from prokaryotes (Escherichia coli) and chloroplasts (pea). The $16 \mathrm{~S}$ rDNA from prokaryotes has no restriction site for $B c l$ I. Predicted sizes are in kilobase. 


\section{RESULTS}

DNA amplification of YVD-symptomatic plants. The bacteria cultivated from symptomatic and asymptomatic plants were identified as species of: Klebsiella, Acinetobacter, Escherichia, Enterobacter, Pseudomonas, and Bacillus. Species from each of these genera were found in both symptomatic and asymptomatic plants. To avoid PCR amplification of DNA from species such as these, which were not specifically associated with disease, phloem tissue, shown by electron microscopy to harbor a disease-associated BLO (5), was prepared prior to extraction of DNA for use as PCR templates. Primers used to amplify a sequence of the $16 \mathrm{~S}$ rDNA of the citrus-greening BLO (20) amplified DNAs (protocol I) from RNase-treated DNA extracted from symptomatic and asymptomatic plants (Fig. 1 and Table 2). Sizes of fragments obtained from symptomatic and asymptomatic plants were similar, except for a $0.153-\mathrm{kb}$ fragment that was consistently amplified in all (72 of 72) symptomatic plants, but not in 27 of 28 of asymptomatic plants (Table 2). A 0.15-kb fragment was also amplified from DNA of E. coli and Brucella abortus (data not shown). The nucleotide sequence of the YVD $0.153-\mathrm{kb}$ fragment determined from the PCR product was unrelated to $16 \mathrm{~S}$ rDNA, but was $84 \%$ identical to a portion of the E. coli ilvA gene encoding threonine deaminase.

TABLE 3. Polymerase chain reaction (PCR) results from fungi and bacteria using PCR protocol II, III, and IV for detection of plants infected by the yellow vine disease bacterium-like organism (BLO)

\begin{tabular}{|c|c|c|c|}
\hline Organism & PRC II ${ }^{\mathrm{a}}$ & PRC III ${ }^{b}$ & PRC IV ${ }^{c}$ \\
\hline Escherichia coli & + & - & - \\
\hline Pantoea ananatis & + & - & - \\
\hline Brucella abortus & + & - & - \\
\hline Serratia marcescens & + & + & - \\
\hline Spiroplasma citri & + & - & - \\
\hline Acremonium cucurbitacearum & - & - & - \\
\hline Fusarium solani & - & - & - \\
\hline F. equiseti & - & - & - \\
\hline F. semitectum & - & - & - \\
\hline F. oxysporum f. sp. niveum race 0 & - & - & - \\
\hline F. oxysporum f. sp. niveum race 1 & - & - & - \\
\hline F. oxysporum f. sp. niveum race 2 & _- & - & - \\
\hline Monosporascus cannonballus & - & - & - \\
\hline Verticillium dahliae & - & - & _- \\
\hline Macrophomina phaseolina & - & - & - \\
\hline Didymella bryoniae & - & - & - \\
\hline Rhizoctonia solani & - & - & - \\
\hline Plectosporium tabacinum & - & - & - \\
\hline Klebsiella sp. $^{\mathrm{d}}$ & + & - & _- \\
\hline Acinetobacter sp. & + & - & - \\
\hline Pseudomonas sp. ${ }^{\mathrm{d}}$ & + & - & _- \\
\hline Escherichia sp. $^{\mathrm{d}}$ & + & - & - \\
\hline Enterobacter sp. $^{\mathrm{d}}$ & + & - & _ \\
\hline Bacillus sp. $^{\mathrm{d}}$ & + & - & - \\
\hline $\begin{array}{l}\text { DNA from citrus plant infected with } X \text {. } \\
{\text { fastidios } a^{\mathrm{e}}}^{\text {ent }}\end{array}$ & $n t^{f}$ & - & - \\
\hline $\begin{array}{l}\text { DNA from citrus plant infected with citrus- } \\
\text { greening } \text { BLO }^{\mathrm{e}}\end{array}$ & nt & - & - \\
\hline $\begin{array}{l}\text { DNA from strawberry plant infected with } \\
\text { marginal chlorosis of strawberry BLO }\end{array}$ & nt & - & - \\
\hline $\begin{array}{l}\text { DNA from papaya plant infected with papaya } \\
\text { bunchy top prokaryote }\end{array}$ & $\mathrm{nt}$ & - & - \\
\hline
\end{tabular}

${ }^{a}$ PCR using protocol II (PCR II) with universal primers for prokaryotic 16S rDNA was considered positive (+) if the $1.5-\mathrm{kb}$ band was present and negative (-) if the band was absent, as indicated in Figure 2, lanes 5 and 6.

${ }^{b}$ PCR using protocol III (PCR III) with YV1-YV2 primers was considered positive (+) if the $0.643-\mathrm{kb}$ band was present and negative (-) if the band was absent, as indicated in Figure 8.

c PCR using protocol IV (PCR IV) with YV1-YV3 primers was considered positive (+) if the $1.433-\mathrm{kb}$ band was present and negative $(-)$ if the band was absent, as indicated in Figure 9.

${ }^{\mathrm{d}}$ Bacteria isolated from symptomatic and asymptomatic plants.

e DNA from healthy plants were also PCR (-).

${ }^{\mathrm{f}} \mathrm{nt}=$ not tested.
A 1.5-kb fragment was amplified by protocol II from DNA of both the symptomatic and asymptomatic watermelon and squash plants using primers known to amplify the $16 \mathrm{~S}$ rDNA from prokaryotes and chloroplasts (Fig. 2A, lanes 5 and 6). Chloroplast $16 \mathrm{~S}$ rDNA has one or more restriction sites for $B c l$, while the prokaryotic 16S rDNA has none (Fig. 2B). Single EcoRI sites in these two rDNAs are located at different positions, such that EcoRI digestion of chloroplast DNA gives a 1.31-kb fragment plus a small remnant and EcoRI digestion of prokaryotic DNA gives 0.87- and $0.67-\mathrm{kb}$ fragments (Fig. 2B). The 1.5-kb fragment was also amplified from DNA extracted from 20 bacterial isolates cultivated from symptomatic and asymptomatic plants, as well as from $S$. citri and Pantoea ananatis, but was not amplified from DNA extracted from the selected soilborne fungi (Table 3). Consistent with the presence of a prokaryotic rDNA in symptomatic plants, the $B c$ II digestion of the PCR products yielded two fragments (1.5 and $1.2 \mathrm{~kb}$ ) from symptomatic plants (Fig. 2A, lane 3) but only one fragment $(1.2 \mathrm{~kb})$ from asymptomatic plants (Fig. 2A, lane 4). EcoRI digestion yielded three fragments $(1.3,0.9$, and $0.7 \mathrm{~kb})$ from the symptomatic plants (Fig. 2A, lane 1), but the $1.5-\mathrm{kb}$ fragment from asymptomatic plants was resistant to EcoRI treatment (Fig. 2A, lane 2), again suggesting the presence of prokaryotic rDNA in symptomatic plants.

Prior BclI digestion of DNA templates from asymptomatic plants for 2,4 , and $8 \mathrm{~h}$ decreased amplification of the 1.5 -kb fragment (Fig. 3, lanes 7, 8, 11, 14, and 15), and digestion for $12 \mathrm{~h}$ abolished amplification of the fragment (Fig. 3, lanes 3 and 4). However, prior $B c l$ I digestion of symptomatic plant DNA templates did not alter the DNA products (Fig. 3, lanes 1, 2, 5, 6, 9, 10, 12, and 13). The $1.5-\mathrm{kb}$ fragment from symptomatic plants (DNA template treated for $12 \mathrm{~h})$ was cleaved into two fragments $(0.7$ and $0.9 \mathrm{~kb})$

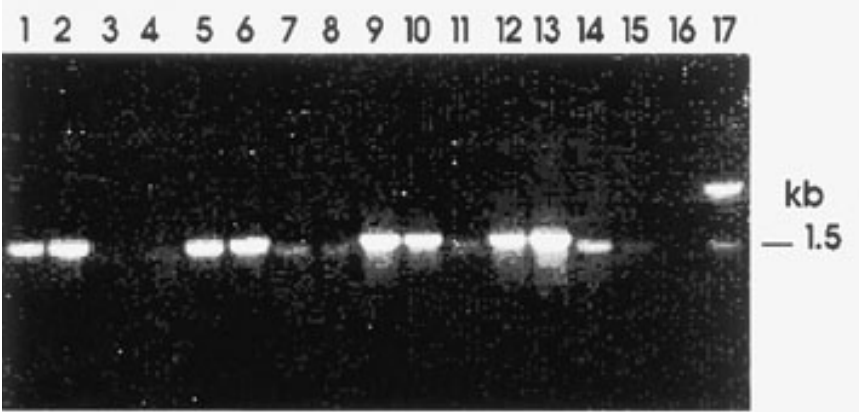

Fig. 3. Agarose gel electrophoresis of polymerase chain reaction (PCR) products using protocol II from symptomatic and asymptomatic plants obtained from a DNA template that was subjected to $B c l$ I digestion for different times before PCR. Lanes 1, 2, 5, 6, 9, 10, 12, and 13 are PCR products from DNA of symptomatic plants; lanes $3,4,7,8,11,14$, and 15 are PCR products from DNA of asymptomatic plants. Lanes 1, 2, 3, and 4 were digested for $12 \mathrm{~h}$; lanes 5, 6, 7, and 8 were digested for $8 \mathrm{~h}$; lanes 9,10 , and 11 were digested for 4 $\mathrm{h}$; and lanes $12,13,14$, and 15 were digested for $2 \mathrm{~h}$. Lane 16 is a negative control with no DNA in the reaction and lane 17 contains molecular weight standards.

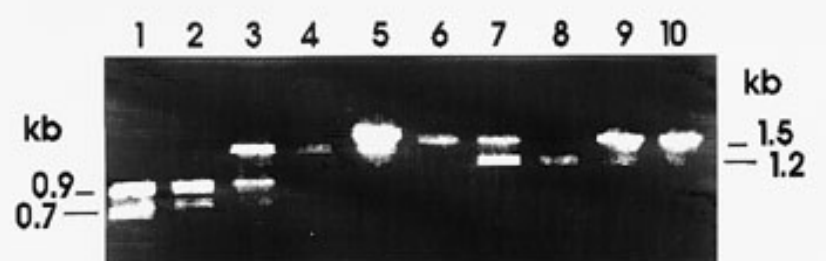

Fig. 4. Agarose gel electrophoresis of digested polymerase chain reaction (PCR) products. The PCR products were digested with EcoRI (lanes 1, 2,3, and 4), or with $B c l$ I (lanes 5, 6, 7, and 8), or not digested (lanes 9 and 10). DNA template had been (lanes 1, 2, 5, and 6) or had not been \{lanes 3,4, 7, 8, and 9) digested with $\mathrm{BclI}$ prior to PCR. Protocol II PCR products from symptomatic plants (lanes 1, 2, 3, 5, 6, 7, and 9) or from asymptomatic plants (lanes 4, 8, and 10). 
by $E c o$ RI (Fig. 4, lanes 1 and 2), but the fragments were resistant to $B c l$ I treatment (Fig. 4, lanes 5 and 6).

Nucleotide sequences from the ends of $1.5-\mathrm{kb}$ fragments amplified from EcoRI-digested or BclI-digested DNA of asymptomatic plants and symptomatic plants were determined from the PCR products. The fragments from EcoRI-digested templates from two symptomatic and two asymptomatic plants were $>99 \%$ identical to one another (data not shown). The sequences for BclI-digested fragments amplified from nine symptomatic plants were $99 \%$ identical to one another, but $67 \%$ different from $1.5-\mathrm{kb}$ fragments amplified from partially $B c l$ I-digested DNA of asymptomatic plants (data not shown). The $1.5-\mathrm{kb}$ fragment amplified from $B c l$ I-digested template from symptomatic plants was cloned and the insert completely sequenced (GenBank accession number U82807) (Fig. 5).

Phylogenetic relationships of the YVD BLO. The secondary structure of the fragment consisting of nucleotides 119 to 260 from the 16S rDNA sequence of the YVD prokaryote was similar to that of $16 \mathrm{~S}$ rDNA region of the gamma proteobacteria (Fig. 6) (30). Signature sequences characteristic of gamma-3 proteobacteria (30) were present in the determined sequence, indicating that the $16 \mathrm{~S}$ rDNA sequence is that of a gamma-3 proteobacterium (Table 4).

A search of databanks for sequences closely related to the $16 \mathrm{~S}$ rDNA sequence obtained from symptomatic plants indicated that the highest scoring matches were from gamma-3 proteobacteria. For phylogenetic analysis, 16 of the highest scoring sequences,

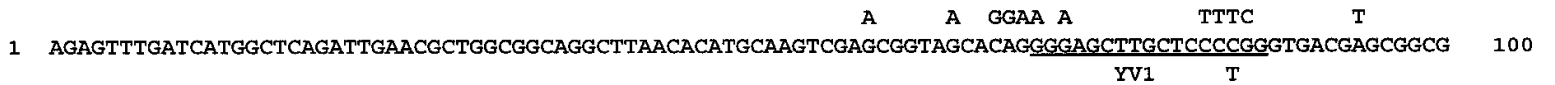

101 GACGGGTGAGTAATGTCTGGGAACTGCCTGATGGAGGGGGATAACTACTGGAAACGGTAGCTAATACCGCATAACGTCGCAAGACCAAAGAGGGGGACC CAGCCACACTGGAGCI A

A 401 TAACTCCGTGCCAGCAGCCGCGGTAATACGGAGGGTGCAAGCGTTAATCGGAATTACTGGGCGTAAAGCGCACGCAGGCGGIITGTTAAGTCAGATGTGA C $\quad T$ T C C CGCTGTAAACGATGTCGAT"T"TGGAGGTTGTGCCCTTGAGGCGTGGCTrTCCGGAGCTAACGCGTTIAA $\mathrm{G}$ AACTCAAATGAATTGACGGGGGCTCC C C $\begin{array}{ccccc} & \text { T } & \text { AGAAT } & \text { CG } & \text { A } \\ 1001 & \text { TTTCCAGAGATGGATTGGTGCCTTCGGGAACTCTGAGACAGGTGCTGCATGGCTGTCGTCAGCTCGTGTTGTGAACT }\end{array}$ C 1101 CGCAACCCTTATCCTTTGTTGCCAGCGGTTCGGCCGGGAACTCAAAGGAGACTGCCAGTGATAAACTGGAGGAAGGTGGGGATGACGTCAAGTCATCATG G CC $\quad C$ C $\quad G \quad$ C 1201 GCCCTTACGAGTAGgGCTACACACGTGCTACAATGGCGTATACAAAGAGAAGCGACCTTCGCGAGA. CAAGCGGA. CTCATAAAGTACGTCGTAGTCCGG A 1301 ATTGGAGTCTGCAACTCGACTCCATGAAGTCGGAATCGCTAGTAATCGTAGATCAGAATGCTACGGTGAATACGTTCCCGGGCCTTGTACACACCGCCCG G G 400

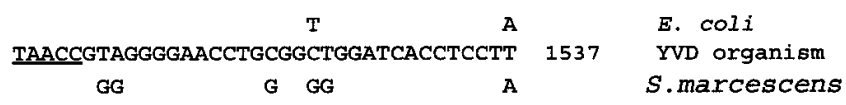

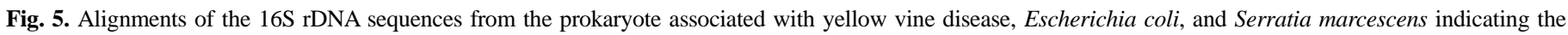

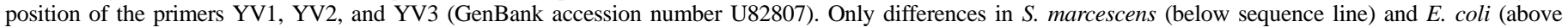
sequence line) sequences relative to that isolated from yellow vine disease-affected plants are shown. YV1, YV2, and YV3 primer positions are underlined. 
with no more than one representative per genus, were chosen. The analysis indicated that the sequence from symptomatic plants was derived from the same sequence lineage as the $16 \mathrm{~S}$ rDNA of Serratia marcescens (Fig. 7). The divergence points of most of the other gamma-3 proteobacterial sequences from the hypothetical common gamma-3 ancestors could not be reliably distinguished from one another. The tree suggests that the organism whose $16 \mathrm{~S}$ rDNA was amplified is clearly distinct from, and only distantly related to, the citrus-greening BLO, "Liberobacter sp." (an alpha proteobacterium).

Primers for detection of plants affected by YVD. Alignments of the $16 \mathrm{~S}$ rDNA sequences from symptomatic plants, Serratia marcescens, and E. coli revealed few differences among these sequences (Fig. 5). A region in which the plant and E. coli sequences differed was chosen for design of primer YV1 and a region in which the plant and Serratia marcescens sequences differed was the basis for design of primer YV3. PCR protocol III used YV1 and YV2 primers and amplified the expected 0.64-kb fragment from symptomatic plants (Table 5 and Fig. 8), but no PCR products were produced from DNA from asymptomatic plants (Table 5); bacteria cultivated from the symptomatic or asymptomatic tissue, E. coli, Pantoea ananatis, or S. citri; or selected soilborne fungal pathogens of cucurbits, healthy plants, or plants infected with the citrus-greening BLO, with the strawberry marginal chlorosis BLO, with the papaya bunchy top prokaryote, or with Xylella fastidiosa (Table 3). A 0.64-kb fragment was also amplified when DNA from Serratia marcescens was used as template (Table 3). PCR protocol IV used YV1 and YV3 primers and amplified the expected

A
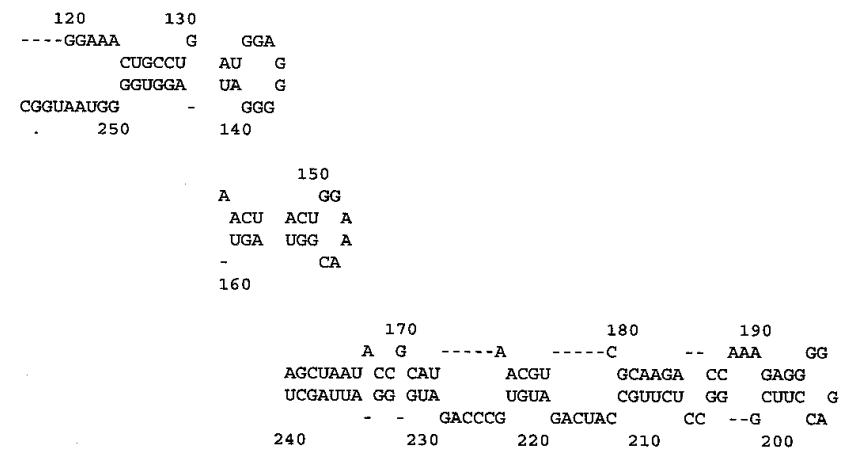

B
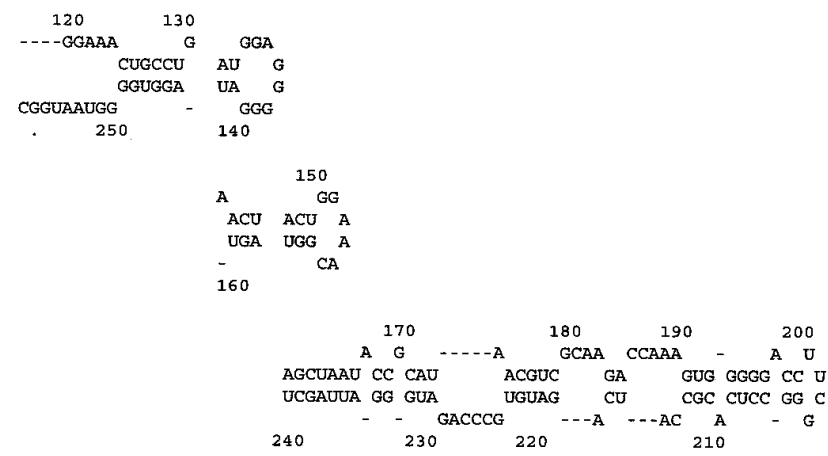

Fig. 6. Predicted secondary structures of nucleotides 119 to 260 of the $16 \mathrm{~S}$ rDNA of the prokaryote associated with $\mathbf{A}$, yellow vine disease and of $\mathbf{B}$, Escherichia coli, a representative of the gamma proteobacteria. The structures were predicted using FOLD software from the Genetics Computer Group package (Madison, WI). 1.43-kb fragment from freshly prepared DNA from the symptomatic plants (Table 5 and Fig. 9). PCR was negative for asymptomatic plants (Table 5 and Fig. 9), E. coli, Serratia marcescens, Pantoea ananatis, $S$. citri, selected soilborne fungal pathogens of cucurbits, and bacteria cultured from symptomatic or asymptomatic plants (Table 3).

\section{DISCUSSION}

In a previous study to determine the etiology of YVD, structures similar to BLOs were consistently observed in the phloem of symptomatic plants, but not in asymptomatic plants (5). In this study, a bacterial $16 \mathrm{~S}$ rDNA sequence was consistently associated with symptomatic plants, but was absent from asymptomatic plants. The strong association suggests that the sequence is from the YVD BLO observed by electron microscopy (5). The identification of this sequence provides a useful diagnostic tool for the detection of YVD-affected plants.

Initial amplification of a $0.153-\mathrm{kb}$ fragment in the symptomatic plants using the citrus-greening BLO primers indicated that these primers differentiated plants affected by YVD from nonaffected plants. However, they are not useful for routine identification of YVD-affected plants, because they amplify a similar fragment in other bacteria. In addition, the amplification of disease nonspecific fragments by this protocol may complicate the use of this protocol for diagnosis. The similarity of the $0.153-\mathrm{kb}$ sequence to a segment of the $E$ coli gene encoding threonine deaminase was the first molecular indication that prokaryotic DNA was present in symptomatic plants.

PCR protocol II, using primers that amplify the $16 \mathrm{~S}$ rDNA from prokaryotes and chloroplasts, reliably amplified a prokaryotic $16 \mathrm{~S}$

TABLE 4. Positions of the identifying signatures of the gamma-3 proteobacteria in the $16 \mathrm{~S}$ rDNA sequence of the yellow vine disease bacterium-like organism

\begin{tabular}{lc}
\hline Signature RNA sequence & Position in the $16 \mathrm{~S}$ rDNA sequence \\
\hline AUCAUG & 9 to 14 \\
AUCCCUAG & 275 to 282 \\
CACAAUG & 363 to 369 \\
UUACUCG & 478 to 484 \\
UCAAUG & 500 to 505 \\
AAUACCRG & 708 to 715 \\
CUUCCG & 846 to 851 \\
GUUAAAACUCAAAUG & 896 to 910 \\
AACUUUCCAG & 998 to 1,007 \\
CAACCCUUAUCCUUUG & 1,103 to 1,118 \\
AACUCUG & 1,129 to 1,135 \\
AACUCAARG & 1,139 to 1,147 \\
CAAAAG & 1,420 to 1,425 \\
\hline
\end{tabular}

TABLE 5. Comparison of yellow vine disease (YVD) symptomatic and asymptomatic watermelon, squash, and cantaloupe plants by polymerase chain reaction (PCR) using protocol III (PCR III) and protocol IV (PCR IV)

\begin{tabular}{|c|c|c|c|}
\hline \multirow[b]{2}{*}{ Location, crop, and cultivar } & \multicolumn{2}{|c|}{ Symptomatic ${ }^{\mathrm{a}}$} & \multirow{2}{*}{$\begin{array}{c}\text { Asymptomatic }^{\mathrm{b}} \\
\text { PCR III and } \\
\text { IV }+ \text { c/total }\end{array}$} \\
\hline & $\begin{array}{c}\text { PCR III +c/ } \\
\text { total }\end{array}$ & $\begin{array}{c}\text { PCR IV +c/ } \\
\text { total }\end{array}$ & \\
\hline Texas, watermelon, Jubilee & $35 / 35$ & $35 / 35$ & $0 / 5$ \\
\hline Texas, watermelon, Desert Storm & $10 / 10$ & $10 / 10$ & $0 / 6$ \\
\hline Oklahoma, watermelon, multiple cvs. & $7 / 7$ & $7 / 7$ & $0 / 7$ \\
\hline Oklahoma, squash, Peto-PC391 & $20 / 20$ & $20 / 20$ & $0 / 10$ \\
\hline Oklahoma, cantaloupe, Magnum 45 & $5 / 5$ & $\mathrm{nt}^{\mathrm{d}}$ & $0 / 5^{\mathrm{d}}$ \\
\hline Texas, cantaloupe, Magnum 45 & $5 / 5$ & nt & $0 / 5^{\mathrm{d}}$ \\
\hline
\end{tabular}

${ }^{a}$ Samples were considered symptomatic of YVD if the phloem was honeybrown in color

b Samples were considered asymptomatic of YVD if phloem was normal in color.

c Samples were considered positive (+) by PCR III if the $0.643 \mathrm{~kb}$-band was visible on the gel as in Figure 8, or by PCR IV if the $1.433-\mathrm{kb}$ band was visible as in Figure 9. PCR was considered negative if the band was absent.

${ }^{\mathrm{d}}$ Cantaloupes were not tested (nt) by PCR IV. 
rDNA from YVD-affected plants. Amplification with these primers of a prokaryotic $16 \mathrm{~S}$ rDNA from diseased plants is a characteristic of BLO-associated diseases such as citrus greening (20) and papaya bunchy top (11). Although the protocol II primers also amplified a rDNA from plastids, the plastid DNA could be distinguished from the prokaryotic DNA by the susceptibility of the amplified DNA to digestion with $B c l$ I and the distinctive fragments resulting from EcoRI digestion. Thus, only plastid DNA was amplified from templates from asymptomatic plants, while both a plastid DNA and prokaryotic DNA were amplified from symptomatic plants. The resistance of the $1.5-\mathrm{kb}$ fragment amplified in the symptomatic plants to $B c l l$, and the cleavage of the fragment into $0.7-$ and $0.9-\mathrm{kb}$ fragments with EcoRI, confirmed that this fragment corresponded to prokaryotic $16 \mathrm{~S}$ rDNA.

The $99 \%$ identity of the sequences of $B c l$ I-resistant PCR fragments from DNA of symptomatic plants to one another and to the cloned $1.5-\mathrm{kb}$ fragment indicated that these $16 \mathrm{~S}$ rDNAs were all amplified from the same organism. The low sequence identity between the $1.5-\mathrm{kb}, B c l$ I-resistant band from symptomatic plants and the $1.5-\mathrm{kb}$ band from asymptomatic plants indicated that amplifi- cation of prokaryote DNA occurred only in the symptomatic plants. Database searches confirmed that the $B c l$ I-resistant band was from prokaryote $16 \mathrm{~S}$ rDNA and the $B c l$-sensitive band was from chloroplast $16 \mathrm{~S}$ rDNA.

Based on data from the current study, the $16 \mathrm{~S}$ rDNA amplified and sequenced from diseased cucurbits belongs to the YVD BLO. The presence of gamma-3 nucleotide signatures in the 16S rDNA of the YVD BLO and the high identity (70 to 96\%) with $16 \mathrm{~S}$ rDNA sequences of the gamma-3 proteobacteria indicate that the YVD BLO is likely a gamma-3 proteobacterium. The $16 \mathrm{~S}$ rDNA sequences have often been used as indicators of the evolutionary relationship of proteobacteria (30). In this case, the data indicate that the YVD BLO is closely related to Serratia marcescens and only distantly related to the citrus-greening BLO. Wells and Raju (31) reported that six fastidious xylem-limited bacteria associated with diseases in different plants were quite similar based on fatty acid composition, but they were distinctly different from known plant-pathogenic bacteria. However, Jagoueix et al. (20) determined that the citrus-greening BLO belonged to the $\alpha$ subdivision of the proteobacteria, which includes both plant and animal bac-

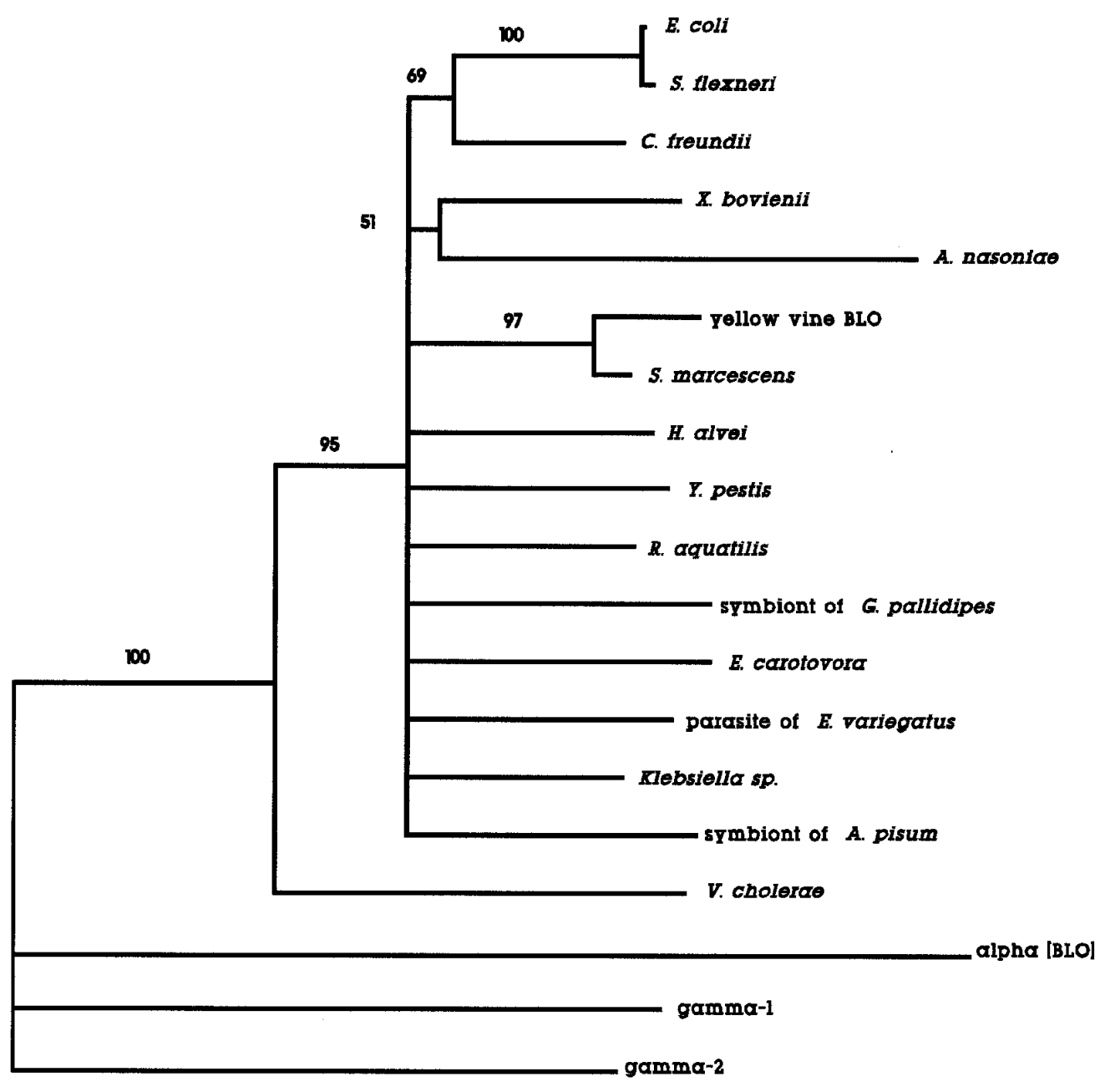

Fig. 7. Phylogenetic relationships based on $16 \mathrm{~S}$ rDNA sequences. Alignments from PILEUP (Genetics Computer Group, Madison, WI) of the 16S rDNA sequence of the yellow vine disease-associated organism with the $16 \mathrm{~S}$ rDNAs of closely related sequences from other prokaryotes were truncated to the length of the shortest sequence. The tree is a consensus between neighbor joining and bootstrapped parsimony. Internal branches not supported by $50 \%$ or more of the bootstrapped analyses were collapsed. Lengths of horizontal lines are proportional to phylogenetic distance, except for the outgroups. Vertical distances are arbitrary. Numbers next to internal branches indicate the percentage of 100 bootstrapped replicates in which that branch was found. The group, NCBI accession number for the 16S rDNA sequence, and the name of bacteria used for phylogenetic analysis are as follows: gamma-3 group: M90801, Arsenophonus narsoniae; Z14096, bacterial parasite of Euscelidius variegatus; M99060, bacterial endosymbiont of Glossina pallidipes; M27040, bacterium symbiotic with Acyrthosiphon sp.; M59291, Citrobacter freundii; M59149, Erwinia carotovora; J01859, Escherichia coli; M59155, Hafnia alvei; U31076, Klebsiella sp.; X07652, Proteus vulgaris; X79939, Rahnella aquatilis; M59160, Serratia marcescens; X80679, Shigella flexneri; X74696, Vibrio cholerae; X82252, Xenorhabdus bovienii; Z7537, Yersinia pestis; Alpha: L22532, Liberobacter sp. (citrus-greening bacterium-like organism); gamma-1 group: M211292, Wolbachia persica; and gamma-2 group: X93484, Ectothiorhodospioraceae sp. The alpha, gamma-1, and gamma-2 groups were used as outgroups for the analysis. 
terial pathogens. The relatedness of the YVD BLO with the enterobacteriaceae suggests that the YVD BLO evolved from a group of bacteria associated with eukaryotes. Several 16S rDNAs with high similarity to the YVD BLO $16 \mathrm{~S}$ rDNA corresponded to uncultured, unidentified bacterial symbionts of invertebrates, including a gamma-3 proteobacterium parasite of the leafhopper, Euscelidius variegatus (9) (Fig. 7). Insect transmissibility is a common characteristic of BLOs $(19,25)$. To date, experiments to determine insect transmissibility of the YVD BLO have been inconclusive, but previous research demonstrated that the rate of disease development and incidence were reduced by insecticide treatment (6). Duthie et al. (15) reported that the YVD was not binomially distributed but aggregated, a pattern consistent with insect transmission.

The three primers (YV1, YV2, and YV3) designed for this work were useful for identification of YVD-affected plants and differentiation between symptomatic and asymptomatic plants. The failure to obtain PCR products from the bacteria cultured from either symptomatic and asymptomatic plants indicated that the primers did not cross-react with bacteria commonly found in watermelon or squash plants, so the presence of these bacteria in the tissue of cucurbit plants does not interfere in PCR detection of the YVD BLO. The negative PCR results with selected BLO, bacteria, and fungi also confirmed the specificity of the primers, suggesting that PCR can be used for detection of YVD-affected plants and perhaps prevent misdiagnosis of the disease. Failure to obtain the 0.64-kb fragment with protocol III with the BLOs tested indicated that the YVD BLO is different from the citrus-greening BLO, the prokaryote that causes papaya bunchy top, the BLO that causes marginal chlorosis of strawberry, and Xylella fastidiosa. The phylogenetic analysis confirmed the distinction between the citrus-greening BLO and the YVD BLO.

The reason that fresh DNA was necessary for amplification using the YV1-YV3 primers in protocol IV, but not using YV1-YV2 primers in protocol III, was not determined. It may be that some sequences of the fragment required for the amplification of the $1.433-\mathrm{kb}$ band degraded easily, but that this degradation does not affect the template required for amplification of the $0.64 \mathrm{~kb}$ fragment with protocol III.

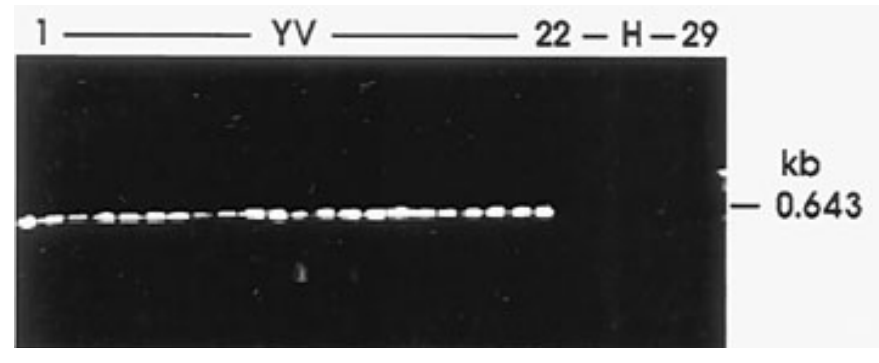

Fig. 8. Agarose gel electrophoresis of polymerase chain reaction products from symptomatic (lanes 1 through 22) and asymptomatic (lanes 23 to 29) watermelon plants using YV1-YV2 primers (protocol III).

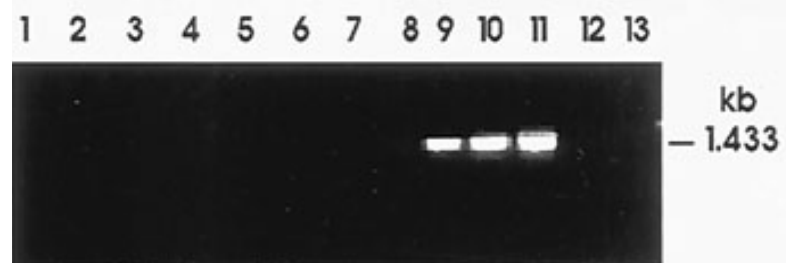

Fig. 9. Agarose gel electrophoresis of polymerase chain reaction (PCR) products from symptomatic and asymptomatic watermelon plants using YV1YV3 primers (protocol IV). Lanes 1 to 5, bacteria cultivated from five different symptomatic watermelon plants; lane 6, Spiroplasma citri; lane 7, Escherichia coli; lane 8, Serratia marcescens; lanes 9, 10, and 11, PCR products from symptomatic watermelon plants; and lanes 12 and 13, PCR products from asymptomatic plants.
Serratia marcescens and Serratia plymuthica have been reported as endophytic bacteria in root and stem tissue of sweet corn and cotton (23). However, cross-reaction of primers YV1-YV2 with Serratia marcescens when using protocol III should not be a serious problem. The Serratia marcescens $0.64-\mathrm{kb}$ fragment can be distinguished from the YVD BLO fragment by digestion with AluI, since their restriction patterns differ (data not shown). Although protocol IV did not amplify a product from Serratia marcescens DNA, protocol III is recommended for detection of YVD-affected plants, because the latter is more rapid and less expensive. To obtain a positive reaction with protocol III, only $1 \mathrm{U}$ of Taq polymerase per $100 \mu \mathrm{l}$ of reaction, $100 \mu \mathrm{M}$ dNTPs, and 25 cycles of amplification were required, and previously frozen DNA could be used. Protocol IV required $2 \mathrm{U}$ of $\mathrm{Taq}$ polymerase per $100 \mu \mathrm{l}$ of reaction, 30 to 35 cycles of amplification, and $200 \mu \mathrm{M}$ dNTPs, and worked only with freshly isolated DNA.

Preliminary studies, in which PCR was done on samples from different tissues of symptomatic watermelon plants, indicated that primers YV1-YV2 can also amplify DNA from complete crown tissue, xylem, or cortex. Amplification was always strongest in the phloem and barely detectable in the cortex or xylem (data not shown). The use of phloem DNA assures the highest titer of the YVD BLO.

Our results indicate that PCR amplification of a $0.64-\mathrm{kb}$ fragment using protocol III can be used as a reliable method to detect the YVD BLO in cantaloupe, watermelon, and squash. Although the causal agent of YVD has not been cultured and transmission of the agent has not been accomplished, the results from this investigation demonstrated that a gamma-3 proteobacterium was consistently associated with affected plants. These findings support the consistent observations of BLOs in the phloem of symptomatic cantaloupe, squash, and watermelon plants (5). This is the first report of a gamma-3 proteobacterium associated with BLO diseases. Additional work is currently underway to transmit the YVD agent, and if possible, to complete the steps of Koch's postulates.

\section{ACKNOWLEDGMENTS}

This research was supported by Specific Cooperative Agreement 586222-5-012 between the Department of Plant Pathology, University of Nebraska, Lincoln, and the United States Department of Agriculture, Agricultural Research Service, Lane, OK 74555. We thank J. Blair for providing the facilities of the Department of Biochemistry and Molecular Biology, Oklahoma State University; J. Cushman from the Recombinant DNA/ Protein Resource Facility, Oklahoma State University, for technical advice; and A. Dillard, D. Baze, and B. Anderson for their technical support.

\section{LITERATURE CITED}

1. Altschul, S. F., Gish, W., Miller, W., Myers, E. W., and Lipman, D. J. 1990. Basic local alignment search tool. J. Mol. Biol. 215:403-410.

2. Ausubel, F. M., Brent, R., Kingston, R. E., Moore, D. D., Seidman, J. G., Smith, J. A., and Struhl, K. 1987. Current Protocols in Molecular Biology. John Wiley \& Sons, New York.

3. Avila, J. F., Bruton, B. D., Fletcher, J., and Pair, S. 1996. Yellow vine of cucurbits in central Texas and Oklahoma. (Abstr.) Phytopathology 86:S104.

4. Avila, J. F., Bruton, B. D., Sherwood, J., Fletcher, J., and Pair, S. D. 1996. Amplification of DNA from yellow vine affected watermelon by polymerase chain reaction. (Abstr.) Phytopathology 86:S75-76.

5. Bruton, B. D., Fletcher, J., Pair, S. D., Shaw, M., and Sittertz-Bhatkar, H. 1998. Association of a phloem-limited bacterium with yellow vine disease in cucurbits. Plant Dis. 82:512-520.

6. Bruton, B. D., Pair, S. D., Popham, T. W., and Cartwright, B. O. 1995. Occurrence of yellow vine, a new disease of squash and pumpkin, in relation to insect pests, mulches, and soil fumigation. Subtrop. Plant Sci. 47:53-58.

7. Bruton, B. D., Pair, S. D., and Wann, E. V. 1995. Yellow vine disease of watermelon and cantaloupe in central Texas and Oklahoma. Pages 151159 in: Proc. Cucurbitaceae '94. G. E. Lester and J. R. Dunlap, eds. Gateway Printing, Edinburg, TX.

8. Bruton, B. D., Pair, S. D., and Wann, E. V. 1995. Yellow vine disease of watermelon and cantaloupe in Texas and Oklahoma. U.S. Dep. Agric. 
SCARL 101

9. Campell, B. C., and Purcell, A. H. 1993. Phylogenetic affiliation of BEV, a bacterial parasite of the leafhopper Euscelidius variegatus, on the basis of the 16S rDNA sequences. Curr. Microbiol. 26:37-41.

10. Chen, T. A., and Davis, R. E. 1979. Cultivation of spiroplasmas. Pages 65-82 in: The Mycoplasmas. Vol. 3. R. F. Whitcomb and J. G. Tully, eds. Academic Press, New York.

11. Davis, M. J., Kramer, J. B., Ferweda, F. H., and Bruner, B. R. 1996. Association of a bacterium and not a phytoplasma with papaya bunchy top disease. Phytopathology 86:102-109.

12. Davis, M. J., Purcell, A. H., and Thomson, S. V. 1980. Isolation media for Pierce's disease bacterium. Phytopathology 70:425-429.

13. Davis, M. J., Thomson, S. V., and Purcell, A. H. 1980. Etiological role of the xylem-limited bacterium causing Pierce's disease in almond leaf scorch. Phytopathology 70:472-475.

14. Davis, M. J., Whitcomb, R. F., and Gillaspie, G., Jr. 1983. Fastidious bacteria of plant vascular tissue and invertebrates including so-called Rickettsia-like bacteria. Pages 2172-2188 in: The Prokaryotes, Phytopathogenic Bacteria. M. P. Starr, ed. Springer-Verlag, New York.

15. Duthie, J. A., Bruton, B. D., and Pair, S. D. 1993. Abundance and spatial aggregation of yellow vine in crops of watermelon and muskmelon. (Abstr.) Phytopathology 83:465.

16. Felsenstein, J. 1989. Phylogeny inference package. Cladistics 5:164-166.

17. Garnier, M., Danel, N., and Bové, J. M. 1984. Aetiology of citrus greening disease. Ann. Microbiol. (Paris) 135A:169-179.

18. Garnier, M., Martin-Gross, G., and Bové, J. M. 1987. Monoclonal antibodies against the bacterium-like organism associated with citrus greening disease. Ann. Microbiol. (Paris) 138:639-650.

19. Hopkins, D. 1977. Disease caused by leafhopper-borne, Rickettsia-like bacteria. Annu. Rev. Phytopathol. 17:277-294.

20. Jagoueix, S., Bové, J. M., and Garnier, M. 1994. The phloem limited bacterium of citrus is a member of the subdivision of Proteobacteria. Int. J. Syst. Bacteriol. 44:379-386.

21. Klein, M., Dabush, S., and Bar-Joseph, M. 1979. A preliminary report on the occurrence of bacterium-like organisms in both phloem and xylem tissues of stunted Melaleuca armilaris plants. Phytoparasitica 7:169-175.

22. Lee, I.-M., and Davis, R. E. 1983. Phloem-limited prokaryotes in the sieve elements isolated by enzyme treatment in disease plant tissues. Phytopathology 73:1540-1543.

23. McInroy, J. A., and Kloepper, J. W. 1994. Studies on indigenous endophytic bacteria of sweet corn and cotton. Pages 19-28 in: Molecular Ecology of Rhizosphere Microorganisms. F. O. O'Gara, D. N. Dowling, and B. Boeston, eds. VCH, Weinheim, Germany.

24. Nourrisseau, J. G., Lansac, M., and Garnier, M. 1993. Marginal chlorosis of a new disease of strawberries associated with a bacterium-like organism. Plant Dis. 77:1055-1059.

25. Purcell, A. H., and Hopkins, D. L. 1996. Fastidious xylem-limited bacterial plant pathogens. Annu. Rev. Phytopathol. 34:131-151.

26. Rumbos, I., Sikora, R. A., and Nienhaus, F. 1977. Rickettsia-like organisms in Xiphinema index Thorne \& Allen found associated with yellows diseases of grapevines. Z. Pflanzenkr. Pflanzenschutz 84:240-243.

27. Schneider, B., Ahrens, U., Kirkpatrick, B. C., and Seemüller, E. 1993. Classification of plant-pathogenic mycoplasma-like organisms using restriction-site analysis of PCR-amplified 16S rDNA. J. Gen. Microbiol. 139:519-527.

28. Sha, Y., Chuang, W., and Jingning, Z. 1986. Studies on isolation, culture, and pathogenicity of dieback of chinaberry caused by bacteria-like organism. J. South China Agric. 7:21-27.

29. Steiner, K. G., Nienhaus, F., and Marschall, K. J. 1977. Rickettsia-like organism associated with a decline of coconut palms in Tanzania. Z. Pflanzenkr. Pflanzenschutz 84:345-351.

30. Weisburg, W. G., Barns, S. N., Pelletier, D. A., and Lane, D. J. 1991. 16S rDNA amplification for phylogenetic study. J. Bacteriol. 173:697-703.

31. Wells, J. M., and Raju, B. C. 1984. Cellular fatty acid composition of six fastidious, gram-negative, xylem-limited bacteria from plants. Curr. Microbiol. 10:231-236.

32. Windsor, I. M., and Black, L. M. 1973. Evidence that clover club leaf is caused by a rickettsia-like organism. Phytopathology 63:1139-1148. 